\title{
Correspondence
}

\section{Behavioural-cognitive psychotherapy training for psychiatrists}

DEAR SIRS

In behavioural-cognitive psychotherapy training for psychiatrists (Psychiatric Bulletin, January 1993, $17,1-4)$ the author states that there has been an impressive development in behavioural and cognitive therapies, while ignoring the role that clinical psychologists have had in pioneering this work in the NHS.

Most, if not all, clinical psychologists are extremely skilled in cognitive-behavioural techniques, the theoretical basis of which is begun during their undergraduate studies and built upon during clinical psychologists' two to three years of training. If psychiatrists want to receive training in cognitivebehavioural psychotherapy they perhaps ought to look towards clinical psychologists to provide it rather than polarising the two professions even further by looking elsewhere. Psychiatrists might also make better use of existing clinical psychology services when considering the referral of clients to other services.

Psychiatrists and clinical psychologists need to work more closely together and the provision of such training would benefit both professions; providing an understanding of how the other works, and facilitating the formation of closer professional relationships, which could only benefit patients.

Clinical Psychologist

RICHARD KERRY

Traumatic Stress Clinic

University College \&

Middlesex School of Medicine

London WIN 8AA

\section{Reply}

Dear SirS

Thank you for giving me the opportunity to reply to Mr Kerry's letter in which it seems he is annoyed at my emphasis on the role of psychiatrists in the development of behavioural and cognitive psychotherapy (BCPT). I question this criticism, as in fact, as well as citing psychiatrists such as Beck, Marks and Wolpe I also cited psychologists such as Ellis, Rachman and Strupp. Moreover, I would not argue with his statement that many clinical psychologists are skilled in BCPT.

The crucial issue I discussed in my article was the one epitomised by this remark made by a psychiatrist "these treatments are psychological: leave them to the psychologists". I had put forward the argument that as it is psychiatrists who head multidisciplinary teams, it is imperative for psychiatrists to become educated in BCPT: "If psychiatrists are not trained in BCPT it leaves them therapeutically impotent, and therefore less able to lead multidisciplinary teams".

On the issue of who should provide the training, I agree with Mr Kerry that many clinical psychologists do often provide this to a very high standard, and should continue to do so where they have the local expertise. However, I would favour training as a collaborative venture, giving equal weight to psychologists and psychiatrists, thus avoiding "polarising the two professions".

My article was intended to make psychiatrists more aware of BCPT along with the training and service implications. I implied that if we did not do this we might have to look to our laurels, and I feel this even more strongly after reading Mr Kerry's letter.

BCPT is too important to leave to psychologists!

Springfield University Hospital RICHARD STERN

61 Glenburnie Road

London SWI7 7DJ

\section{Selective serotonin re-uptake inhibitors: use in depression}

Dear Sirs

In the above article by Professor Ferrier and colleagues, (Psychiatric Bulletin, 1992, 16, 737-739), I was struck by the continued belief in the older antidepressants which persists within our profession. Professor Ferrier et al comment on the increased risk of suicide reported with fluoxetine, yet there is no discussion of the danger in overdose of the older antidepressants. Only a small number of suicides die from taking such anti-depressant medication, but I feel that any strategy which will reduce the increasing levels of suicide is to be welcomed, yet many of our colleagues persist in using out-dated, unsafe medication.

If drugs, such as amitriptyline and others were presented for licence currently, then the CSM would surely not see fit to license them.

Royal Cornhill Hospital

Alastair N. Palin 